\title{
FoxO1 is a critical regulator of hepatocyte lipid deposition in chronic stress mice
}

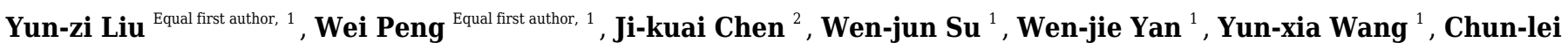 \\ Jiang ${ }^{\text {Corresp. } 1}$ \\ ${ }^{1}$ Department of Stress Medicine, Faculty of Psychology,, Second Military Medical University, Shanghai, China \\ ${ }^{2}$ Department of Health Toxicology, Faculty of Naval Medicine, Second Military Medical University, Shanghai, China \\ Corresponding Author: Chun-lei Jiang \\ Email address: cljiang@vip.163.com
}

FoxO1 is involved in lipid metabolisms. However, its role in chronic stress-related nonalcoholic fatty liver disease (NAFLD) is unclear. The scientific premise of our study was based on the finding that FoxO1 expression is increased in liver of mice after chronic stress. It is important to understand the mechanisms involved in the activation of FoxO1 and how its function affects the liver lipid deposition. We employed a murine chronic stress model, in which mice were treated by plantar electrical stimulation and restraint for 6 weeks, and a cellular model, in which Hepa 1-6 cells were treated with corticosterone. We also used a pharmacologic approach as1842856, a highly specific FoxO1 inhibitor. Lipid metabolism related genes levels were measured by qRT-PCR and the lipid levels by biochemical detection. We show that the level of FoxO1 is significantly elevated in the liver of chronic stress mice. Transcription factor FoxO1 regulates a lipid synthesis phenotype of hepatocyte that is involved in the development and progression of NAFLD. We have shown that inhibition of FoxO1 induced phenotypic conversion of hepatocytes and down-regulates lipid synthesis genes expression by hepatocytes, which contribute to lipid deposition in NAFLD. At the cellular level, the inhibitor of FoxO1 as1842856 can also attenuated the lipid deposition of Hepa1-6 cells induced by corticosterone. Targeting FoxO1 is a novel therapeutic target for chronic stress-related NAFLD. 


\section{FoxO1 is a Critical Regulator of Hepatocyte Lipid Deposition in chronic stress mice}

2

3 Yun-zi Liu ${ }^{1, \pi}$, Wei Peng ${ }^{1, \pi}$, Ji-kuai Chen², Wen-jun Su${ }^{1}$, Wen-jie Yan ${ }^{1}$, Yun-xia Wang1, Chun-lei

4 Jiang 1 ,

5

$6{ }^{1}$ Department of Stress Medicine, Faculty of Psychology, Second Military Medical University, 7 No.800 Xiangyin Road, Shanghai 200433, PR China

82 Department of Health Toxicology, Faculty of Naval Medicine, Second Military Medical

9 University, Shanghai 200433, PR China

10

11 Y Yun-zi Liu and Wei Peng contributed equal to this work.

12

13 Corresponding Author:

14 Chun-lei Jiang

15 Department of Stress Medicine, Faculty of Psychology, Second Military Medical University, 800

16 Xiangyin Road, Shanghai 200433, China

17 Email address: cljiang@vip.163.com 


\section{Abstract}

19 Forkhead box $\mathrm{O} 1$ (FoxO1) is a potent transcriptional regulator of pancreatic $\beta$-cell function and

20 lipid metabolism. However, its role in chronic stress-related nonalcoholic fatty liver disease

21 (NAFLD) is unclear. The scientific premise of our study was based on the finding that FoxO1

22 expression is increased in the livers of mice after chronic stress. It is important to understand the

23 effect of FoxO1 activation in chronic stress-induced liver lipid deposition. We employed a

24 murine chronic stress model, in which mice were treated by plantar electrical stimulation and 25 restraint for 6 weeks, and a cellular model, in which Hepa 1-6 cells were treated with 26 corticosterone. We also used a pharmacologic approach, with as 1842856 , a highly specific

27 FoxO1 inhibitor. Lipid metabolism-related gene levels were measured by quantitative reverse 28 transcription polymerase chain reaction (qRT-PCR) and the lipid levels were measured by 29 biochemical detection. We show that the level of FoxO1 is significantly elevated in the liver of 30 chronic stress mice. Transcription factor FoxO1 regulates a lipid synthesis phenotype of 31 hepatocytes that is involved in the development and progression of NAFLD. We have shown that 32 inhibition of FoxO1 induced phenotypic conversion of hepatocytes and downregulates lipid 33 synthesis gene expression by hepatocytes, which contribute to lipid deposition in NAFLD. At the 34 cellular level, the inhibitor of FoxO1 as 1842856 can also attenuate the lipid deposition of Hepa1356 cells induced by corticosterone. Targeting FoxO1 is a novel therapeutic target for chronic 36 stress-related NAFLD. 


\section{Introduction}

38 The incidence of nonalcoholic fatty liver disease (NAFLD) is $20-30 \%$ globally (Henao-

39 Mejia et al., 2012). The lipid deposition of the liver, especially the abnormal deposition of

40 triglycerides (TG), is the basis of the pathogenesis of NAFLD (Piccinin et al., 2018). The

41 correlation between the occurrence of NAFLD and chronic stress has received increasing

42 attention in recent years (Ashtari et al., 2015). Our previous result and others' studies have

43 confirmed that chronic stress could lead to liver lipid deposition and inflammation, which lead to

44 the development of NAFLD (Fu et al., 2010; Liu et al., 2014). However, the specific mechanism

45 of chronic stress-induced liver lipid deposition is not clear.

46 FoxO1 is a member of the forkhead $\mathrm{O}$ family and plays a key role in lipid metabolism (Li et

47 al., 2017). Activation of FoxO1 was detected during lipid deposition in the liver (Kim et al., 48 2016); activated FoxO1 was also found to lead to an increase in the output of very low-density 49 lipoprotein (triglyceride-rich particles) in the liver, resulting in hypertriglyceridemia (Kim et al., 50 2011); the expression and activity of FoxO1 were increased in patients with NAFLD and 51 correlated positively with the severity of the disease (Valenti et al., 2008). Matsumoto et al. 52 found that the transfection of FoxO1 in the liver increased the TG content of the liver 53 (Matsumoto et al., 2006). Thus, we hypothesized that chronic stress leads to liver lipid deposition 54 by activation of FoxO1. Our previous study demonstrated that chronic stress induces liver lipid 55 deposition and FoxO1 activation in mice (Liu et al., 2014). However, the causal relationship 56 between FoxO1 and liver lipid deposition during chronic stress is unclear. The molecular 57 mechanisms of stress-induced lipid metabolism disorders are also unclear.

58 In this study, 6 weeks of plantar electrical stimulation and restraint were used to induce the mouse chronic stress. FoxO1 activity inhibitor as 1842856 was used to verify the role of FoxO1 in this model. After 6-week stress exposure, we performed lipid deposition tests and measured 
61 TG synthesis genes and cholesterol metabolism-related genes to explore if and how FoxO1

62 influences the lipid deposition in a chronic stress animal model. It may provide new targets for

63 drug prevention and treatment of stress-related lipid metabolic disorders.

64

65

66

67

68

69

70

71

72

73

74 75

76

77 78

\section{Materials \& Methods}

Reagents and Antibodies

FoxO1 inhibitor (as1842856) and Cortisol were purchased from Sigma-Aldrich (St. Louis, MO, USA). Fetal calf serum (FCS) was obtained from Hyclone (Logan, UT, USA). Penicillin and streptomycin were obtained from Invitrogen (Carlsbad, CA, USA). FoxO1, p-FoxO1, and $\beta$ Actin antibodies were obtained from Abcam (Cambridge, MA, USA). IRDye 800CW donkey anti-goat and IRDye 800CW goat anti-rabbit secondary antibodies were both purchased from LICOR Biosciences (LI-COR, Inc., Lincoln, NE, USA). The Real-time PCR reactions were performed using SYBR Premix Ex Taq ${ }^{\mathrm{TM}}$ (Takara Biotechnology). Hematoxylin-eosin (H\&E) and oil red $\mathrm{O}$ were purchased from Nanjing Jiancheng Science and Technology Company.

\section{Animals and Chronic Stress Protocols}

C57BL/6J male mice, 5-7 weeks age, were purchased from Slaccas Laboratory Animal Company (Shanghai, China). Mice were housed in plastic home-cages in a temperature controlled room at $24^{\circ} \mathrm{C}$, under a $12 \mathrm{~h}: 12 \mathrm{~h}$ illumination cycle (lights on at 8:00 AM). To stress animals, we used a modified version of the protocol described previously (Liu et al., 2014). For chronic stress, each mouse was administered electric foot shock (10:00, 7.5s/2min, 15min, 25V) and restraint stress (19:00-21:00) every day for 42 consecutive days before evaluations. Nonstress mice (control group) remained in the home cage and kept isolated from stressed animals. FoxO1 inhibitor group were administered as 1842856 at $30 \mathrm{mg} / \mathrm{kg}$ by gavage during the 42 days. The control group was treated with equal volume solvent by gavage. Animal's weight and food 
85 intake were measured every week. All animal procedures used in this study were approved by

86 the Institutional Animal Care and Use Committee of the Second Military Medical University

87 (No. 20161027, Shanghai, China) and Shanghai Science and Technology Committee (SYXK-

88 HU-2012-0003).

$89 \quad$ Hematoxylin-Eosin $(H \& E)$ and oil red o staining

90 Following fixation of the livers or cells with $10 \%$ formalin, livers were sliced and stained

91 with H\&E for histological examination. Hepatic lipid content was also determined by staining

92 with Oil Red O (Sigma). Pictures were imaged with a Zeiss microscope (Carl Zeiss Microscopy,

93 Thornwood, NY, USA).

$94 \quad$ Biochemical analysis

95 The serum TG, total cholesterol (TC), and free fatty acid (FFA) were measured by an 96 automatic biochemistry analyzer (Hitachi 7170, Tokyo, Japan). Livers were homogenized at $4^{\circ} \mathrm{C}$ 97 in lysis buffer containing $50 \mathrm{mmol} / \mathrm{L}$ Tris $(\mathrm{pH} 8.0), 150 \mathrm{mmol} / \mathrm{L} \mathrm{NaCl}, 1 \%$ Triton X-100, and $98 \quad 0.5 \%$ sodium deoxycholate. Lipids from the total liver homogenate were extracted using the 99 chloroform/methanol method (2:1), evaporated, and dissolved in 2-propanol. Amounts of TC and 100 TG were measured by an automatic biochemistry analyzer (Hitachi 7170, Tokyo, Japan).

101 For glucose tolerance test (GTT), mice were fasted overnight and injected with $2 \mathrm{mg} / \mathrm{g}$ 102 glucose/body weight. For insulin tolerance test (ITT), mice were fasted for 4 hours and injected 103 with $1 \mathrm{U} / \mathrm{Kg}$ insulin/body weight. The blood glucose levels were monitored at 30 min intervals 104 for $2 \mathrm{~h}$ with an ACCU-CHEK Active Blood Glucose System (Roche) using tail tip blood 105 samples. Serum insulin was determined by mouse insulin ELISA kit which was purchased from 106 R\&D, USA.

$107 \quad$ Cell culture 
Mouse liver cancer Hepa 1-6 cell lines (ATCC CRL-1830) were cultured in Dulbecco's

109

110

111

112

113

114

115

116

117

118

119

120

121

122

123

124

Modified Eagle's Medium (DMEM) (Hyclone Laboratories, Logan, Utah, USA). The medium

contained 10\% fetal bovine serum (FBS) and $100 \mathrm{unit} / \mathrm{mL}$ penicillin and $100 \mathrm{~g} / \mathrm{mL}$ streptomycin in a humidified atmosphere that contained $5 \% \mathrm{CO}_{2}$. Cells were further administrated in DMEM containing $1 \mu \mathrm{M}$ cortisol or $1 \mu \mathrm{M}$ as 1842856 for $48 \mathrm{~h}$.

$q R T-P C R$

Total RNA was isolated with Trizol reagent (Invitrogen, Carlsbad, CA). cDNA was synthesized using PrimeScript ${ }^{\mathrm{TM}}$ RT Master Mix (Takara, Tokyo, Japan). Quantitative real-time PCR was carried out using the One Step TB Green ${ }^{\mathrm{TM}}$ PrimeScript $^{\mathrm{TM}}$ RT-PCR Kit (Takara) according to manufacturer's instructions (Table 1). The $2^{-\Delta \Delta \mathrm{Ct}}$ method was used to calculate the relative expression level by normalizing to $\beta$-Actin levels (Zhao et al., 2019).

\section{Western blot analysis}

Protein samples were prepared by lysing cells or tissues in modified RIPA buffer $[1 \times$ PBS, 1\% Nonidet P-40, 0.1\% sodium dodecyl sulfate, and protease inhibitor cocktail (SigmaAldrich)]. Lysates (50-100 $\mu \mathrm{g})$ were separated on a 10\% SDS-PAGE and transferred to a nitrocellulose membrane. The membrane was probed with the specific primary antibody and secondary antibody and then quantified with Odyssey Infrared Imaging System (LI-COR, Inc., Lincoln, NE, USA) and Image J Software (National Institute of Mental Health, USA).

\section{Statistical analysis}

The data were presented as mean \pm standard error (SEM) and differences considered statistically significant only when $p$-values are less than 0.05 . Data was mainly analyzed using a two-way ANOVA followed by uncorrected Fisher's LSD post hoc test with GraphPad Prism 6 (GraphPad Software, Inc., La Jolla, CA, USA). Two-way ANOVA for repeated measures was 
131 used to analyze the weight curves. Student's t-test was applied to detect significant difference

132 between two groups.

\section{Results}

The levels of FoxO1 protein and mRNA were significantly increased in the liver of mice after 6 weeks of stress, while the FoxO1 inhibitor as1842856 did not affect FoxO1 expression (Fig. 1A, B, and E). The ratio of $p$-FoxO1 protein to FoxO1 was significantly decreased in the stress group (Fig. 1A, D) but significantly increased in the stress+as1842856 group. Phosphorylated FoxO1 protein is the inactive form of FoxO1 (Pan et al., 2017). The changes in the mRNA levels of PEPCK and G6Pase, the classical FoxO1 regulated target genes, were consistent with the changes in the activity of FoxO1 (Fig. 1F, G). intake of the control group increased slowly and steadily, while the stress group did not increase significantly. At the 6th week of stress, the body weight of the stress group was significantly

147 lower than that of the control group (Fig. 2A). The food intake at the 5 th week of stress also 148 decreased significantly (Fig. 2B). There was no significant difference in body weight and food 149 intake between the control group and the as1842856 group. We also tested fasting blood glucose, 150 postprandial blood glucose, insulin, glucose tolerance, and insulin tolerance in 4 groups of mice 151 after 6 weeks of stress. The results showed no significant difference between the 4 groups (Fig. 152 2C-G).

153 As1842856 reduced adipogenesis in the liver of chronic stress mice 
After 6 weeks of stress, hematoxylin and eosin (HE) staining of livers in mice showed 155 hepatocyte fatty degeneration: enlarged hepatocytes, loose and reticular cytoplasm, individual 156 cytoplasm was transparent, and shaped like a balloon (Fig. 3A). Oil red O staining showed 157 brownish red lipid droplet formation (Fig. 3A). FoxO1 inhibitor as1842856 significantly reduced 158 the lipid deposition induced by chronic stress (Fig. 3A). Furthermore, the morphology of 159 hepatocytes in the livers of mice fed with as1842856 still displayed normal architecture around 160 the central veins (Fig. 3A). We further quantified the TG and cholesterol levels in the livers of 161 mice. The results showed that FoxO1 inhibitors significantly reduced the liver TG content 162 induced by chronic stress, while cholesterol content had no significant change (Fig. 3B and C).

163 The levels of serum TG (Fig. 3D) and free fatty acid (FFA, Fig. 3E, p<0.001) were 164 significantly increased in the chronic stress group. Both TG and FFA were significantly reduced 165 in the stress+as1842856 group compared with the stress group (Fig. 3D and E). There was no 166 statistical difference in serum cholesterol after chronic stress and as1842856 treatment (Fig. 3F). Effects of as 1842856 on the $m R N A$ expression of lipoprotein metabolism-related genes in mice after 6 weeks of chronic stress

169 The mRNA expression of fatty acid synthase (FASN) was significantly increased in the chronic stress group compared with the control group (Fig. 4A). However, the mRNA expression 171 of FASN in the stress+as1842856 group was significantly decreased compared with the stress 172 group (Fig. 4A). There were no significant differences between the 4 groups in ACC1 or SCD1 173 (Fig. 4B and C). The mRNA expression of fatty acid binding protein (FATP) and fatty acid 174 binding protein (FABP) in the chronic stress group was significantly increased compared with 175 the control group (Fig. 4D and E). As1842856 significantly decreased the mRNA expression of 176 FATP and FABP, which was elevated by the chronic stress (Fig. 4D and E). There were no 
177 significant differences in the other synthetically-related gene, CD36 (Fig. 4F). We also found no

178 statistically significant differences in the mRNA expression of genes related to fatty acid 179 oxidation, such as PPAR $\alpha$, Acox1, Lcad, Mcad, Pdk4, Cpt1a, and Ucp2 (Fig. 4G-N).

180 Effects of as 1842856 on the mRNA expression of cholesterol metabolism-related genes in 181 mice after 6 weeks of chronic stress

182 We found that the mRNA expression of HMG-CoAR and CYP7A1 was significantly 183 increased in the stress group. The mRNA expression of HMG-CoAR and CYP7A1 in the 184 stress+as1842856 group was significantly lower than that in the stress group (Fig. 5A and B). 185 However, there was no statistical difference in the synthetic-related gene cholesterol-regulating 186 element binding transcription factor 1C (SREBP-1c) and the cholesterol transport-related gene 187 ABCG1 (Fig. 5C and D).

188 As1842856 inhibited FoxO1 activation in the Hepal-6 cells after corticosterone treatment 189 We also demonstrated the effect of as 1842856 on FoxO1 activation and adipogenesis in the 190 Hepa1-6 cells. The levels of FoxO1 protein and mRNA were significantly increased in the 191 corticosterone group, compared with the control group (Fig. 6A-C). The $p$-FoxO1 protein and the $192 p$-FoxO1/FoxO1 ratio were also significantly decreased after corticosterone treatment (Fig. 6A193 D). The FoxO1 inhibitor as 1842856 significantly increased the $p$-FoxO1 protein and $p$-FoxO1/ 194 FoxO1 value (Fig. 6A-D). The change of the classical target gene PEPCK regulated by FoxO1 195 was consistent with the change of FoxO1 activity (Fig. 6E and F). As1842856 reduced adipogenesis in the Hepa1-6 cells after corticosterone treatment

After treatment with $1 \mu \mathrm{M}$ of corticosterone for $48 \mathrm{~h}$, oil red $\mathrm{O}$ staining indicated that most Hepa1-6 cells showed obvious brown-red lipid droplets. The corticosterone+as 1842856 group 199 showed no obvious lipid droplets (Fig. 7A). 
FASN mRNA expression was significantly increased in the corticosterone group compared 201 with the control group (Fig. 7B). The corticosterone+as1842856 group showed a significant 202 decrease in FASN mRNA expression compared with the corticosterone group (Fig. 7B). Other 203 synthetically related genes, ACC1 and SCD1 showed no significant difference between the 4 204 groups (Fig. 7C and D).

\section{Discussion}

This study demonstrated that chronic stress induced lipid deposition in the livers of mice, 207 which were mainly TG. Liver TG synthesis genes and FFA uptake genes were significantly upregulated in mRNA levels after chronic stress. These changes can be blocked by as 1842856 , 209 the inhibitor of FoxO1. Moreover, at the cellular level, the changes in lipid metabolism of Hepa1-6 cells induced by corticosterone are basically the same as those in animal chronic stress experiments. The inhibitor of FoxO1 as1842856 also attenuated the lipid deposition of Hepa1-6 cells induced by corticosterone. Our study confirms the important regulatory role of FoxO1 in 213 stress-induced lipid metabolism disorders.

214 Chronic stress refers to continuous physical or psychological forms of tension and pressure. 215 Macedo et al. (Macedo et al., 2012) found that the chronic stress model mice, created by a 216 narrow living environment and high-calorie diets, gained less weight than normal-fed mice.

217 However, there was no difference between the two groups on the ratios of body weight to body 218 length. It is suggested that mice fed a high-calorie diet may have abdominal obesity. Czech et al. 219 (Czech et al., 2013) found that chronic stress model mice caused by crowded communities have 220 significant oxidative stress and inflammatory response in the liver under normal feeding 221 conditions. Our previous study (Liu et al., 2014) found that liver index (total liver/body 222 weight $\times 100$ ) and liver TG levels increased significantly in chronic stress model (sustained foot 
223 stimulation and tethered for 12 weeks) mice. Hepatic cell adipose degeneration was found by

224 liver section staining. Although the stress patterns and models described above are different, they

225 all suggest that stress is associated with hepatic steatosis and inflammatory response.

226 According to our previous results and related literature reports (Kim et al., 2017; Shin et al.,

227 2015; Yamamoto et al., 2002), we used a combination of plantar electrical stimulation and 228 restraint stress to construct a stress model. After 6 weeks of continuous stress, model mice liver 229 TG levels were significantly elevated. Liver fatty degeneration was also demonstrated by the 230 liver section staining. It indicated that chronic stress causes lipid deposition in the livers of mice, 231 and the model was successfully constructed. It is consistent with the results of our previous study 232 (Liu et al., 2014).

233 The possible mechanism of stress-induced hepatic lipid deposition is considered to be 234 related to long-term activation of the hypothalamic-pituitary-adrenal cortex (HPA) axis (van 235 Bodegom et al., 2017). The activated HPA axis releases glucocorticoids. On the one hand, 236 glucocorticoids enhance the decomposition of lipolysis hormones, promote the decomposition of 237 adipose tissue, and release a large amount of FFA into the blood. On the other hand, 238 glucocorticoids promote lipid formation and deposition of hepatocytes. At the same time, the 239 hippocampus has an inhibitory effect on HPA axis activation. Under long-term chronic stress, a 240 large number of hippocampal neurons undergo dysfunction or death by the chronically elevated 241 glucocorticoids, losing their inhibitory effect on the HPA axis, and leading to the massive release 242 of glucocorticoids (Kim et al., 2013; Sakamoto et al., 2015; Zhu et al., 2014). In our study, the 243 FFA content in the blood increased significantly after chronic stress. Corticosterone or cortisol is 244 the main hormone of the pituitary adrenocortical axis secreted by the adrenal cortex in response 245 to environmental challenges (McEwen, 2007; Quijije, 2015; Kant et al., 1987). At the same time, 
246 we also investigated the effect of corticosterone in hepatocyte lipid deposition. Lipid droplets

247 were found in Hepa1-6 cells, which were treated with corticosterone for 48 hours. This suggests

248 that chronic stress may cause liver lipid deposition by elevating the corticosterone level.

249 Our previous experiments found that FoxO1 may be involved in stress-induced lipid 250 metabolism disorders. FoxO1 is a member of the FOXO transcription factor. FOXO is widely 251 expressed in a variety of tissues, including the liver, and is a key effector molecule in cell 252 homeostasis, metabolism, and stress response (Ma et al., 2018). It acts as a pre-transcriptional 253 regulator that binds to chromatin (Riedel et al., 2013; Zaret \& Carroll, 2011) and initiates or 254 inhibits transcription (Furuyama et al., 2000; Ramaswamy et al., 2002; Webb et al., 2013). 255 FoxO1 is a typical forkhead protein transcription factor, a key signaling molecule downstream of 256 the insulin/ insulin-like growth factor-1 (IGF-1) signal and has been shown to be involved in the 257 regulation of glucose metabolism (O'Neill et al., 2016). FoxO1 binds to adjacent sites in the 258 insulin response elements (IREs) within the insulin-like growth factor binding protein 1 259 (IGFBP1) and glucose-6-phosphatase (G6Pase) promoters to initiate gene activation (Nakae et 260 al., 2001a; Matsumoto et al., 2007; Yeagley et al., 2001). Active nuclear FOXO1 also binds the transcriptional coactivator peroxisome proliferative activated receptor- $\gamma$ coactivator $1-\alpha(\mathrm{PGC} 1 \alpha)$ 262 to coordinate a gluconeogenic transcriptional program involving increased expression of 263 glucose-6-phosphatase $(G 6 p c)$ and cytosolic phosphoenolpyruvate carboxykinase (Pckl) 264 (Puigserver et al., 2003; Nakae et al., 2001b). In addition, FOXOs mediate the effects of insulin 265 on adipocyte differentiation, neuropeptide transcription and processing, and $\beta$-cell health (Nakae 266 et al., 2003; Ren et al., 2012; Plum et al., 2009). In recent years, an increasing number studies 267 have shown that FoxO1 is also involved in the regulation of lipid metabolism in the liver. These 268 studies have found that activation of FoxO1 was observed in lipid deposition in the liver (Kim et 
269 al., 2016); activated FoxO1 induced an increase in liver output of very low-density lipoprotein 270 (rich in TG particles) and hypertriglyceridemia (Kim et al., 2011). This study also indicated that 271 FoxO1 does participate in liver lipid deposition caused by chronic stress. On the one hand, we 272 observed changes in FoxO1 protein, mRNA, and phosphorylation levels in stressed mice; on the 273 other hand, liver lipid deposition due to chronic stress is alleviated after the treatment of FoxO1 274 activity inhibitor.

275 To further clarify how FoxO1 regulates liver lipid deposition, this experiment examined the 276 expression levels of genes involved in liver and lipid metabolism. Previous experiments have 277 confirmed that the main component of lipid deposition caused by chronic stress is TG, and the 278 amount of TG in the liver is inseparable from the uptake and synthesis of FFA (Liu et al., 2014).

279 FASN is a key enzyme for the de novo synthesis of endogenous fatty acids and is closely related 280 to lipid metabolism (Jones \& Infante, 2015). FASN mRNA and protein levels were significantly 281 upregulated in fatty liver (Huang et al., 2013). Upregulation of FASN in rat liver is involved in 282 the formation of fatty liver. The FATP family and the FABP family are important protein 283 families that take up fatty acids and are primarily responsible for the transport of extracellular 284 FFA uptake. Studies have confirmed that fatty acid uptake is significantly reduced in hepatocytes 285 286 of FATP knockout mice (Falcon et al., 2010). Purified FATP1 exhibits long-chain and ultralong-chain fatty acyl-CoA synthetase activity (Hall et al., 2003). FABP can be activated by long287 chain FA, PPARs, and toll-like receptor (TLR) agonists, which are involved in sugar, lipid 288 metabolism, and inflammatory processes (Doege et al., 2006; Tan et al., 2002; Wolfrum et al., 289 2001). This study found that FoxO1 increases fatty acid synthesis and intra-hepatic transport of 290 FFA by increasing the expression of FASN, FATP, and FABP and increasing liver TG 291 deposition. ACC1 and SCD1 are two other key enzymes involved in lipogenesis (29925265). 
292 ACC1 and SCD1 showed no significant difference between the 4 groups. This suggested that the 293 expression of FASN, FTAP, and FABP, but not ACC1 or SCD1, are controlled by the 294 transcription factor FoxO1.We also found that FoxO1 did not affect the feeding of mice and fatty 295 acid oxidation in the liver. FoxO1 is a key molecule downstream of insulin, which regulates 296 glucose metabolism. However, chronic stress mice did not show significant glucose metabolism 297 abnormalities in this experiment. We speculate that mice may still be in a compensatory period 298 due to the relatively short stress time. This conclusion requires further experiments to prove by a 299 longer-term chronic stress test.

300 Conclusions

301 In summary, this study demonstrated that chronic stress induced FoxO1 activation and lipid 302 deposition in the livers of mice. Inhibition of FoxO1 attenuated the TG synthesis and fatty acid 303 oxidation induced by the chronic stress. Corticosterone may act as a mediator between FoxO1 304 and chronic stress. The present study indicated that inhibition of FoxO1 may have therapeutic 305 benefits for chronic stress relative fatty liver disease.

\section{Acknowledgements}

307 This research was fully funded by Natural Science Fund of Shanghai (17ZR1437800) (Yun308 zi LIu), National Natural Science Foundation of China (NSFC) (31871171 and 81571169) 309 (Chun-lei Jiang), and (81703267) (Ji-kuai Chen). 


\section{References}

311 Ashtari, S., Pourhoseingholi, M.A., and Zali, M.R. 2015. Non-alcohol fatty liver disease in Asia: Prevention and

312 planning. World J Hepatol 7:1788-1796. 10.4254/wjh.v7.i13.1788

313 Czech, B., Neumann, I.D., Muller, M., Reber, S.O., and Hellerbrand, C. 2013. Effect of chronic psychosocial stress on nonalcoholic steatohepatitis in mice. Int J Clin Exp Pathol 6:1585-1593.

Doege, H., Baillie, R.A., Ortegon, A.M., Tsang, B., Wu, Q., Punreddy, S., Hirsch, D., Watson, N., Gimeno, R.E., and Stahl, A. 2006. Targeted deletion of FATP5 reveals multiple functions in liver metabolism: alterations in hepatic lipid homeostasis. GASTROENTEROLOGY 130:1245-1258. 10.1053/j.gastro.2006.02.006

Falcon, A., Doege, H., Fluitt, A., Tsang, B., Watson, N., Kay, M.A., and Stahl, A. 2010. FATP2 is a hepatic fatty acid transporter and peroxisomal very long-chain acyl-CoA synthetase. Am J Physiol Endocrinol Metab 299:E384E393. 10.1152/ajpendo.00226.2010

Fu, J.H., Sun, H.S., Wang, Y., Zheng, W.Q., Shi, Z.Y., and Wang, Q.J. 2010. The effects of a fat- and sugarenriched diet and chronic stress on nonalcoholic fatty liver disease in male Wistar rats. Dig Dis Sci 55:2227-2236. 10.1007/s10620-009-1019-6

Furuyama, T., Nakazawa, T., Nakano, I., and Mori, N. 2000. Identification of the differential distribution patterns of mRNAs and consensus binding sequences for mouse DAF-16 homologues. BIOCHEMICAL JOURNAL 349:629634.

Hall, A.M., Smith, A.J., and Bernlohr, D.A. 2003. Characterization of the Acyl-CoA synthetase activity of purified murine fatty acid transport protein 1. JOURNAL OF BIOLOGICAL CHEMISTRY 278:43008-43013. 10.1074/jbc.M306575200

Henao-Mejia, J., Elinav, E., Jin, C., Hao, L., Mehal, W.Z., Strowig, T., Thaiss, C.A., Kau, A.L., Eisenbarth, S.C., Jurczak, M.J., Camporez, J.P., Shulman, G.I., Gordon, J.I., Hoffman, H.M., and Flavell, R.A. 2012. Inflammasomemediated dysbiosis regulates progression of NAFLD and obesity. NATURE 482:179-185. 10.1038/nature10809

Huang, Y.Y., Gusdon, A.M., and Qu, S. 2013. Nonalcoholic fatty liver disease: molecular pathways and therapeutic strategies. Lipids in Health and Disease 12:171. 10.1186/1476-511X-12-171

Jones, S.F., and Infante, J.R. 2015. Molecular Pathways: Fatty Acid Synthase. CLINICAL CANCER RESEARCH 21:5434-5438. 10.1158/1078-0432.CCR-15-0126

Kant, G.J., Leu, J.R., Anderson, S.M., and Mougey, E.H. 1987. Effects of chronic stress on plasma corticosterone, ACTH and prolactin. PHYSIOLOGY \& BEHAVIOR 40:775-779.

Kim, D.H., Lee, B., Kim, M.J., Park, M.H., An, H.J., Lee, E.K., Chung, K.W., Park, J.W., Yu, B.P., Choi, J.S., and Chung, H.Y. 2016. Molecular Mechanism of Betaine on Hepatic Lipid Metabolism: Inhibition of Forkhead Box O1 (FoxO1) Binding to Peroxisome Proliferator-Activated Receptor Gamma (PPARgamma). J Agric Food Chem 64:6819-6825. 10.1021/acs.jafc.6b02644

Kim, D.H., Zhang, T., Ringquist, S., and Dong, H.H. 2011. Targeting FoxO1 for hypertriglyceridemia. CURRENT DRUG TARGETS 12:1245-1255.

Kim, J.Y., Yang, S.H., Kwon, J., Lee, H.W., and Kim, H. 2017. Mice subjected to uncontrollable electric shocks show depression-like behaviors irrespective of their state of helplessness. BEHAVIOURAL BRAIN RESEARCH 322:138-144. 10.1016/j.bbr.2017.01.008

Kim, S.H., Moon, I.S., and Park, I.S. 2013. Unique hippocampal changes and allodynia in a model of chronic stress. JOURNAL OF KOREAN MEDICAL SCIENCE 28:946-950. 10.3346/jkms.2013.28.6.946

Li, Y., Ma, Z., Jiang, S., Hu, W., Li, T., Di S, Wang, D., and Yang, Y. 2017. A global perspective on FOXO1 in lipid metabolism and lipid-related diseases. PROGRESS IN LIPID RESEARCH 66:42-49. 10.1016/j.plipres.2017.04.002

Liu, Y.Z., Chen, J.K., Zhang, Y., Wang, X., Qu, S., and Jiang, C.L. 2014. Chronic stress induces steatohepatitis while decreases visceral fat mass in mice. BMC GASTROENTEROLOGY 14:106. 10.1186/1471-230X-14-106 Ma, J., Matkar, S., He, X., and Hua, X. 2018. FOXO family in regulating cancer and metabolism. SEMINARS IN CANCER BIOLOGY 50:32-41. 10.1016/j.semcancer.2018.01.018

Macedo, I.C., Medeiros, L.F., Oliveira, C., Oliveira, C.M., Rozisky, J.R., Scarabelot, V.L., Souza, A., Silva, F.R., Santos, V.S., Cioato, S.G., Caumo, W., and Torres, I.L. 2012. Cafeteria diet-induced obesity plus chronic stress alter serum leptin levels. PEPTIDES 38:189-196. 10.1016/j.peptides.2012.08.007

Matsumoto, M., Han, S., Kitamura, T., and Accili, D. 2006. Dual role of transcription factor FoxO1 in controlling hepatic insulin sensitivity and lipid metabolism. JOURNAL OF CLINICAL INVESTIGATION 116:2464-2472. 10.1172/JCI27047

Matsumoto, M., Pocai, A., Rossetti, L., Depinho, R.A., and Accili, D. 2007. Impaired regulation of hepatic glucose production in mice lacking the forkhead transcription factor Foxol in liver. Cell Metabolism 6:208-216. 
McEwen, B.S. 2007. Physiology and neurobiology of stress and adaptation: central role of the brain. PHYSIOLOGICAL REVIEWS 87:873-904. 10.1152/physrev.00041.2006

Nakae, J., Kitamura, T., Kitamura, Y., Biggs, W.R., Arden, K.C., and Accili, D. 2003. The forkhead transcription factor Foxo1 regulates adipocyte differentiation. DEVELOPMENTAL CELL 4:119-129.

Nakae, J., Kitamura, T., Silver, D.L., and Accili, D. 2001a. The forkhead transcription factor Foxo1 (Fkhr) confers insulin sensitivity onto glucose-6-phosphatase expression. JOURNAL OF CLINICAL INVESTIGATION 108:13591367. 10.1172/JCI12876

Nakae, J., Kitamura, T., Silver, D.L., and Accili, D. 2001b. The forkhead transcription factor Foxo1 (Fkhr) confers insulin sensitivity onto glucose-6-phosphatase expression. JOURNAL OF CLINICAL INVESTIGATION 108:13591367. 10.1172/JCI12876

O'Neill, B.T., Lee, K.Y., Klaus, K., Softic, S., Krumpoch, M.T., Fentz, J., Stanford, K.I., Robinson, M.M., Cai, W., Kleinridders, A., Pereira, R.O., Hirshman, M.F., Abel, E.D., Accili, D., Goodyear, L.J., Nair, K.S., and Kahn, C.R. 2016. Insulin and IGF-1 receptors regulate FoxO-mediated signaling in muscle proteostasis. JOURNAL OF CLINICAL INVESTIGATION 126:3433-3446. 10.1172/JCI86522

Pan, C.W., Jin, X., Zhao, Y., Pan, Y., Yang, J., Karnes, R.J., Zhang, J., Wang, L., and Huang, H. 2017. AKTphosphorylated FOXO1 suppresses ERK activation and chemoresistance by disrupting IQGAP1-MAPK interaction. EMBO JOURNAL 36:995-1010. 10.15252/embj.201695534

Piccinin, E., Villani, G., and Moschetta, A. 2018. Metabolic aspects in NAFLD, NASH and hepatocellular carcinoma: the role of PGC1 coactivators. Nat Rev Gastroenterol Hepatol. 10.1038/s41575-018-0089-3

Plum, L., Lin, H.V., Dutia, R., Tanaka, J., Aizawa, K.S., Matsumoto, M., Kim, A.J., Cawley, N.X., Paik, J.H., Loh, Y.P., DePinho, R.A., Wardlaw, S.L., and Accili, D. 2009. The obesity susceptibility gene Cpe links FoxO1 signaling in hypothalamic pro-opiomelanocortin neurons with regulation of food intake. NATURE MEDICINE 15:1195-1201. 10.1038/nm.2026

Puigserver, P., Rhee, J., Donovan, J., Walkey, C.J., Yoon, J.C., Oriente, F., Kitamura, Y., Altomonte, J., Dong, H., Accili, D., and Spiegelman, B.M. 2003. Insulin-regulated hepatic gluconeogenesis through FOXO1-PGC-1alpha interaction. NATURE 423:550-555. 10.1038/nature01667

Quijije, N. 2015. Updates in the neuroendocrinology of stress and its clinical management. Curr Opin Endocrinol Diabetes Obes 22:319-324. 10.1097/MED.0000000000000176

Ramaswamy, S., Nakamura, N., Sansal, I., Bergeron, L., and Sellers, W.R. 2002. A novel mechanism of gene regulation and tumor suppression by the transcription factor FKHR. CANCER CELL 2:81-91.

Ren, H., Orozco, I.J., Su, Y., Suyama, S., Gutierrez-Juarez, R., Horvath, T.L., Wardlaw, S.L., Plum, L., Arancio, O., and Accili, D. 2012. FoxO1 target Gpr17 activates AgRP neurons to regulate food intake. CELL 149:1314-1326. 10.1016/j.cell.2012.04.032

Riedel, C.G., Dowen, R.H., Lourenco, G.F., Kirienko, N.V., Heimbucher, T., West, J.A., Bowman, S.K., Kingston, R.E., Dillin, A., Asara, J.M., and Ruvkun, G. 2013. DAF-16 employs the chromatin remodeller SWI/SNF to promote stress resistance and longevity. NATURE CELL BIOLOGY 15:491-501. 10.1038/ncb2720

Sakamoto, Y., Ogawa, T., Ogawa, M., Matsuo, Y., Hashikawa, N., and Hashikawa, N. 2015. [Effects of 15-day chronic stress on behavior and neurological changes in the hippocampus of ICR mice]. YAKUGAKU ZASSHIJOURNAL OF THE PHARMACEUTICAL SOCIETY OF JAPAN 135:151-158. 10.1248/yakushi.14-00180

Shin, S., Kwon, O., Kang, J.I., Kwon, S., Oh, S., Choi, J., Kim, C.H., and Kim, D.G. 2015. mGluR5 in the nucleus accumbens is critical for promoting resilience to chronic stress. NATURE NEUROSCIENCE 18:1017-1024. $10.1038 / \mathrm{nn} .4028$

Tan, N.S., Shaw, N.S., Vinckenbosch, N., Liu, P., Yasmin, R., Desvergne, B., Wahli, W., and Noy, N. 2002. Selective cooperation between fatty acid binding proteins and peroxisome proliferator-activated receptors in regulating transcription. MOLECULAR AND CELLULAR BIOLOGY 22:5114-5127.

Valenti, L., Rametta, R., Dongiovanni, P., Maggioni, M., Fracanzani, A.L., Zappa, M., Lattuada, E., Roviaro, G., and Fargion, S. 2008. Increased expression and activity of the transcription factor FOXO1 in nonalcoholic steatohepatitis. DIABETES 57:1355-1362. 10.2337/db07-0714

van Bodegom, M., Homberg, J.R., and Henckens, M. 2017. Modulation of the Hypothalamic-Pituitary-Adrenal Axis by Early Life Stress Exposure. Frontiers in Cellular Neuroscience 11:87. 10.3389/fncel.2017.00087

Webb, A.E., Pollina, E.A., Vierbuchen, T., Urban, N., Ucar, D., Leeman, D.S., Martynoga, B., Sewak, M., Rando, T.A., Guillemot, F., Wernig, M., and Brunet, A. 2013. FOXO3 shares common targets with ASCL1 genome-wide and inhibits ASCL1-dependent neurogenesis. Cell Reports 4:477-491. 10.1016/j.celrep.2013.06.035

Wolfrum, C., Borrmann, C.M., Borchers, T., and Spener, F. 2001. Fatty acids and hypolipidemic drugs regulate peroxisome proliferator-activated receptors alpha - and gamma-mediated gene expression via liver fatty acid binding 
421

422

423

424

425

426

427

428

429

430

431

432

433

434

435

436

437

438 protein: a signaling path to the nucleus. Proc Natl Acad Sci U S A 98:2323-2328. 10.1073/pnas.051619898

Yamamoto, K., Takeshita, K., Shimokawa, T., Yi, H., Isobe, K., Loskutoff, D.J., and Saito, H. 2002. Plasminogen activator inhibitor-1 is a major stress-regulated gene: implications for stress-induced thrombosis in aged individuals. Proc Natl Acad Sci U S A 99:890-895. 10.1073/pnas.022608799

Yeagley, D., Guo, S., Unterman, T., and Quinn, P.G. 2001. Gene- and activation-specific mechanisms for insulin inhibition of basal and glucocorticoid-induced insulin-like growth factor binding protein-1 and phosphoenolpyruvate carboxykinase transcription. Roles of forkhead and insulin response sequences. JOURNAL OF BIOLOGICAL CHEMISTRY 276:33705-33710. 10.1074/jbc.M101215200

Zaret, K.S., and Carroll, J.S. 2011. Pioneer transcription factors: establishing competence for gene expression. Genes Dev 25:2227-2241. 10.1101/gad.176826.111

Zhao, Q., Wang, Q., Wang, J., Tang, M., Huang, S., Peng, K., Han, Y., Zhang, J., Liu, G., Fang, Q., and You, Z. 2019. Maternal immune activation-induced PPARgamma-dependent dysfunction of microglia associated with neurogenic impairment and aberrant postnatal behaviors in offspring. NEUROBIOLOGY OF DISEASE 125:1-13. 10.1016/j.nbd.2019.01.005

Zhu, L.J., Liu, M.Y., Li, H., Liu, X., Chen, C., Han, Z., Wu, H.Y., Jing, X., Zhou, H.H., Suh, H., Zhu, D.Y., and Zhou, Q.G. 2014. The different roles of glucocorticoids in the hippocampus and hypothalamus in chronic stressinduced HPA axis hyperactivity. PLoS One 9:e97689. 10.1371/journal.pone.0097689 


\section{Figure legend}

440 Figure 1. FoxO1 specific inhibitor as 1842856 enhances FoxO1 phosphorylation in mice liver 441 after 6 weeks. Chronic stress increased the protein (A and B) and mRNA lever (E) of FoxO1 442 expression and its downstream genes, G6Pase (F) and PEPCK (G), and decreased the lever of $p$ 443 FoxO1 protein(C) and $p$-FoxO1/FoxO1 (D), while as 1842856 could reverse this effect except the 444 protein and mRNA lever of FoxO1 expression. ${ }^{*} p<0.05,{ }^{* * *} p<0.001$. Date presented as 445 mean \pm SEM, $\mathrm{n}=6$.

446 Figure 2. As1842856 does not affect weight, food intake and glucose metabolic parameters in 447 mice after 6 weeks. (A) Changes in food intake. (B) Changes in body weight. (C) Profiles of 448 blood glucose concentration as function of time upon intraperitoneal injection of glucose (D) 449 Profiles of glucose concentration (percentage of initial value) as a function of time upon 450 intraperitoneal injection of insulin. (E-G) Blood insulin, postprandial blood glucose (PBG), and 451 fasting plasma glucose (FPG). ${ }^{*} p<0.05,{ }^{* *} p<0.01,{ }^{* * *} p<0.001$. Date presented as mean \pm SEM, $452 \mathrm{n}=6$.

453 Figure 3. As1842856 protect mice against stress-induced liver lipid deposition. (A) 454 Representative slides showed hematoxylin and eosin (HE)-stain and Oil red O-stain liver 455 sections from four groups. (B and C) Liver TG and T-CHO concentrations were detected by 456 biochemical test in liver tissue homogenate. (D, E, and F) TG, FFA, and T-CHO concentrations 457 in serum. ${ }^{*} p<0.05,{ }^{* *} p<0.01,{ }^{* * *} p<0.001$. Date presented as mean \pm SEM, $\mathrm{n}=6$.

458 Figure 4. Effects of stress and as1842856 on liver lipid metabolism genes in mice after 6 weeks. 459 (A-C) Relative mRNA levels of genes involved in hepatic TG synthesis. (D-F) Relative mRNA 460 levels of genes involved in fatty acid transport. (G-N) Relative mRNA levels of genes involved 461 in fatty acid oxidation. ${ }^{*} p<0.05,{ }^{* *} p<0.01$. Date presented as mean $\pm \mathrm{SEM}, \mathrm{n}=6$. 
462 Figure 5. Effects of stress and as1842856 on cholesterol metabolism-related genes in mice after

4636 weeks. Liver was harvested and cholesterol metabolism-related genes were determined by 464 realtime-PCR. ${ }^{*} p<0.05,{ }^{* *} p<0.01$. Date presented as mean $\pm \mathrm{SEM}, \mathrm{n}=6$.

465 Figure 6. As1842856 protect Hepa1-6 cells against corticosterone-induced liver lipid deposition.

466 Effects of corticosterone and as1842856 on FoxO1 in Hepa1-6 cells after 48h. Corticosterone $467(1 \mu \mathrm{M})$ increased the protein (A and $\mathrm{B})$ and mRNA lever (E) of FoxO1 expression and its 468 downstream gene, PEPCK (F), AND decreased the lever of $p$-FoxO1 protein (C) and $p$ 469 FoxO1/FoxO1 (D), while as1842856 $(1 \mu \mathrm{M})$ could reverse this effect except the protein and 470 mRNA lever of FoxO1 expression. ${ }^{*} p<0.05, * * p<0.01, * * * p<0.0001$. Date presented as 471 mean \pm SEM, $\mathrm{n}=3$.

472 Figure 7. Effects of corticosterone and as1842856 on lipid deposition and TG synthesis genes in 473 Hepa 1-6 cells after 48h. (A) Representative images showed above from four groups. After 474 treatment with $1 \mu \mathrm{m}$ Corticosterone or/and $1 \mu \mathrm{m}$ as 1842856 for $48 \mathrm{~h}$, the cells were stained with 475 Oil red O. (B) Corticosterone increased the genes' expression of Fasn, while as1842856 could 476 reverse this effect. (C and D) There was no significant difference among the four groups in the 477 genes' expression of ACC1 and SCD1. *** $p<0.001$. Date presented as mean $\pm \mathrm{SEM}, \mathrm{n}=3$. 
Table $\mathbf{1}$ (on next page)

Sequences of primers used for qRT-PCR.

Sequences of primers used for qRT-PCR. 
1 Table 1 Sequences of primers used for qRT-PCR

\begin{tabular}{|c|c|}
\hline Gene name & Sequence $\left(5^{\prime}-3^{\prime}\right)$ \\
\hline FoxO1-F1 & AGTGGATGGTGAAGAGCGTG \\
\hline FoxO1-R1 & GAAGGGACAGATTGTGGCGA \\
\hline Fasn-F1 & CAAGTGTCCACCAACAAGCG \\
\hline Fasn-R1 & GGAGCGCAGGATAGACTCAC \\
\hline Pepck-F1 & TGCGGATCATGACTCGGATG \\
\hline Pepck-R1 & AGGCCCAGTTGTTGACCAAA \\
\hline Scd1-F1 & GGCTAGCTATCTCTGCGCTC \\
\hline Scd1-R1 & GAACTGCGCTTGGAAACCTG \\
\hline HMGCoAR-F1 & ACGATCCTTCCTTATTGGCGG \\
\hline HMGCoAR-R1 & CTCCGGATCTCAATGGAGGC \\
\hline Fatp1-F1 & GGCAAGCTCCAGCACAGGAT \\
\hline Fatp1-R1 & ACCCACGTACACACAGAACG \\
\hline G6Pase-F1 & CGACTCGCTATCTCCAAGTGA \\
\hline G6Pase-R1 & GTTGAACCAGTCTCCGACCA \\
\hline SREBP1c-F1 & GATGTGCGAACTGGACACAG \\
\hline SREBP1c-R1 & CATAGGGGGCGTCAAACAG \\
\hline Cyp7a1-F1 & GGGATTGCTGTGGTAGTGAGC \\
\hline Cyp7a1-R1 & GGTATGGAATCAACCCGTTGTC \\
\hline Abcg1-F1 & СТTTCСТАСТCTGTACCCGAGG \\
\hline Abcg1-R1 & CGGGGCATTCCATTGATAAGG \\
\hline Fabp1-F1 & ATGAACTTCTCCGGCAAGTACC \\
\hline Fabp1-R1 & CTGACACCCCCTTGATGTCC \\
\hline Cd36-F1 & ATGGGCTGTGATCGGAACTG \\
\hline $\mathrm{Cd} 36-\mathrm{R} 1$ & GTCTTCCCAATAAGCATGTCTCC \\
\hline Acc1-F1 & ATGGGCGGAATGGTCTCTTTC \\
\hline Acc1-R1 & TGGGGACCTTGTCTTCATCAT \\
\hline PPAR $\alpha-F 1$ & AGAGCCCCATCTGTCCTCTC \\
\hline PPAR $\alpha-R 1$ & ACTGGTAGTCTGCAAAACCAAA \\
\hline PPAR $\gamma-\mathrm{F} 1$ & TCGCTGATGCACTGCCTATG \\
\hline PPAR $\gamma-\mathrm{R} 1$ & GAGAGGTCCACAGAGCTGATT \\
\hline Pdk4-F1 & AGGGAGGTCGAGCTGTTCTC \\
\hline Pdk4-R1 & GGAGTGTTCACTAAGCGGTCA \\
\hline Cpt1a-F1 & CTCCGCCTGAGCCATGAAG \\
\hline Cpt1a-R1 & CACCAGTGATGATGCCATTCT \\
\hline Acox1-F1 & TAACTTCCTCACTCGAAGCCA \\
\hline Acox1-R1 & AGTTCCATGACCCATCTCTGTC \\
\hline Lcad-F1 & TCTTTTCCTCGGAGCATGACA \\
\hline Lcad-R1 & GACСТСТСТАСТСАСТTСТССАG \\
\hline
\end{tabular}




\section{Mcad-F1}

Mcad-R1

Ucp2-F1

Ucp2-R1

$\beta$-actin-F1

$\beta$-actin-R1
AGGGTTTAGTTTTGAGTTGACGG CCCCGCTTTTGTCATATTCCG TGCACTCCTGTGTTCTCCTG GGGACCTTCAATCGGCAAGA TTCTTGGGTATGGAATCCTGT AGCACTGTGTTGGCATAGAG

2 


\section{Figure 1}

FoxO1 specific inhibitor as1842856 enhances FoxO1 phosphorylation in mice liver after 6 weeks.

Chronic stress increased the protein (A and $B$ ) and mRNA lever (E) of FoxO1 expression and its downstream genes, G6Pase (F) and PEPCK (G), and decreased the lever of $p$-FoxO1 protein(C) and p-FoxO1/FoxO1 (D), while as1842856 could reverse this effect except the protein and mRNA lever of FoxO1 expression. ${ }^{*} p<0.05 \square^{* * *} p<0.001$. Date presented as mean $\pm S E M, n=6$. 
A

$$
\text { Stress }+ \text { Con }+
$$

Con Stress as1842856 as1842856

FoxO1 $82 \mathrm{kDa}$

$\beta$-Actin $42 \mathrm{kDa}$

p-FoxO1 - - $-\cdots$

B-Actin $42 \mathrm{kDa}$

B

C
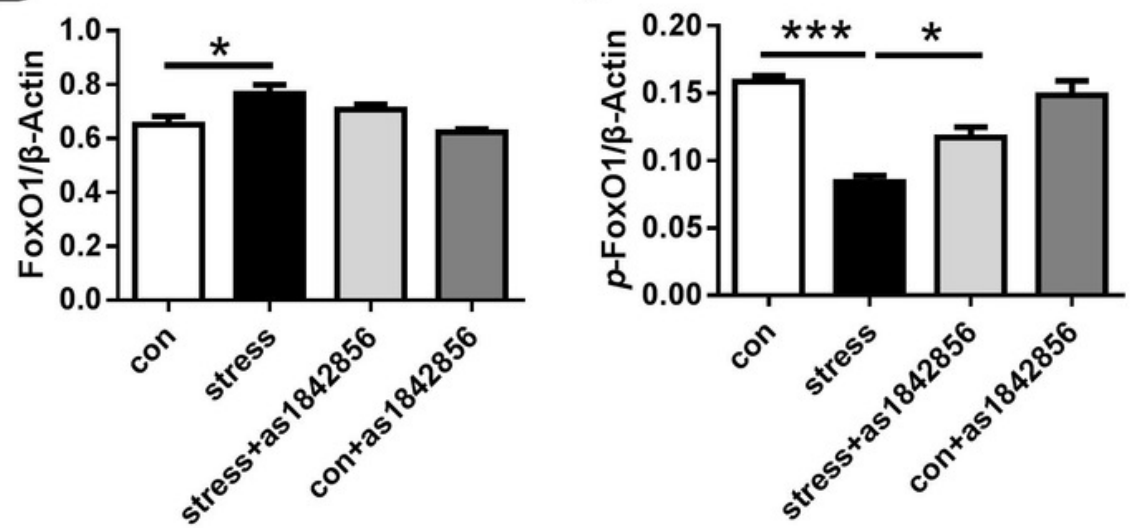

D

E
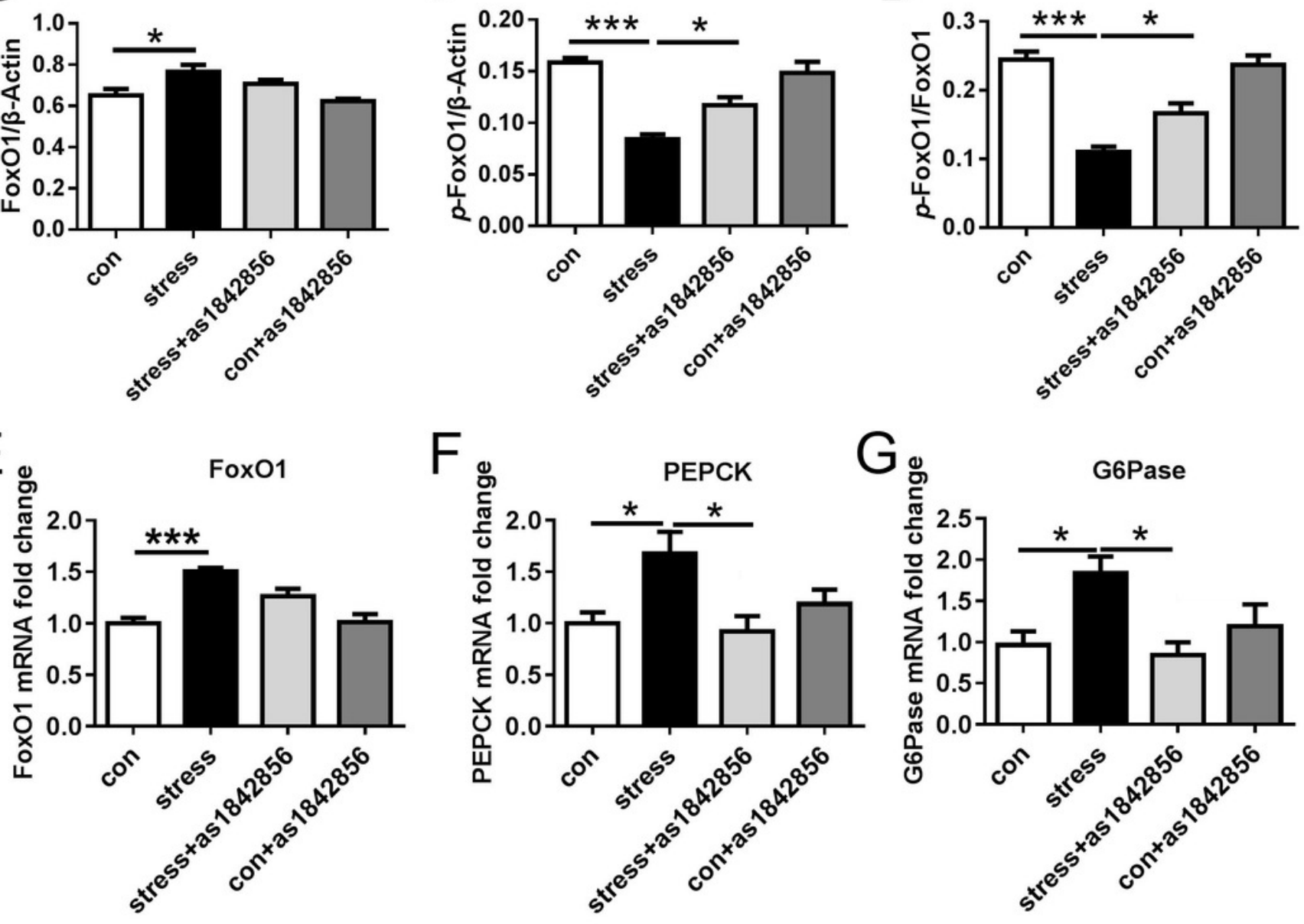


\section{Figure 2}

As1842856 does not affect weight, food intake and glucose metabolic parameters in mice after 6 weeks.

(A) Changes in food intake. (B) Changes in body weight. (C) Profiles of blood glucose concentration as function of time upon intraperitoneal injection of glucose (D) Profiles of glucose concentration (percentage of initial value) as a function of time upon intraperitoneal injection of insulin. (E-G) Blood insulin, postprandial blood glucose (PBG), and fasting plasma glucose (FPG). ${ }^{*} p<0.05,{ }^{* *} p<0.01,{ }^{* * *} p<0.001$. Date presented as mean $\pm \mathrm{SEM}, \mathrm{n}=6$. 

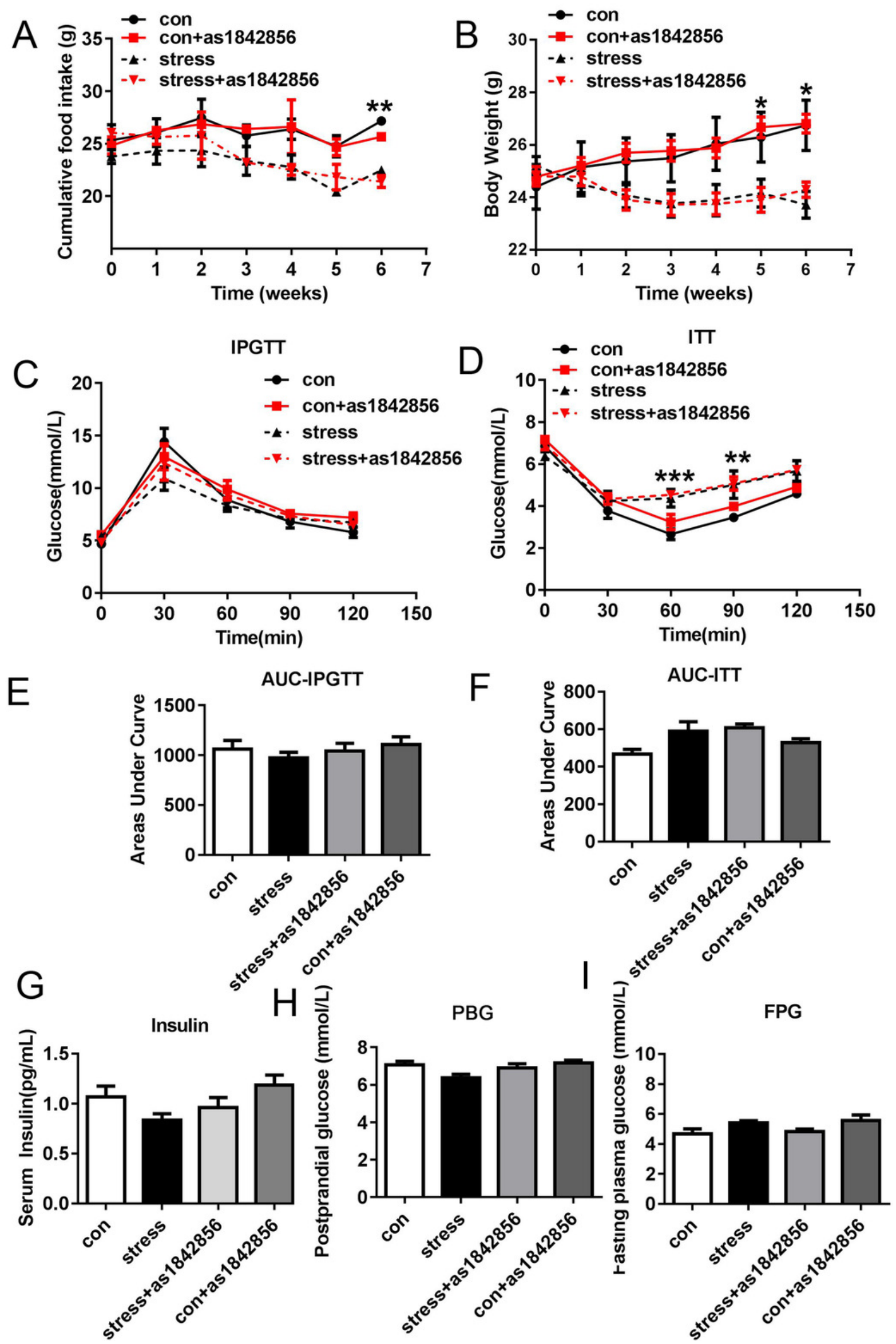
Figure 3

As1842856 protect mice against stress-induced liver lipid deposition.

(A) Representative slides showed hematoxylin and eosin (HE)-stain and Oil red O-stain liver sections from four groups. ( $\mathrm{B}$ and $\mathrm{C}$ ) Liver TG and T-CHO concentrations were detected by biochemical test in liver tissue homogenate. (D, E, and F) TG, FFA, and T-CHO concentrations in serum. ${ }^{*} p<0.05,{ }^{* *} p<0.01,{ }^{* * *} p<0.001$. Date presented as mean $\pm \mathrm{SEM}, \mathrm{n}=6$. 


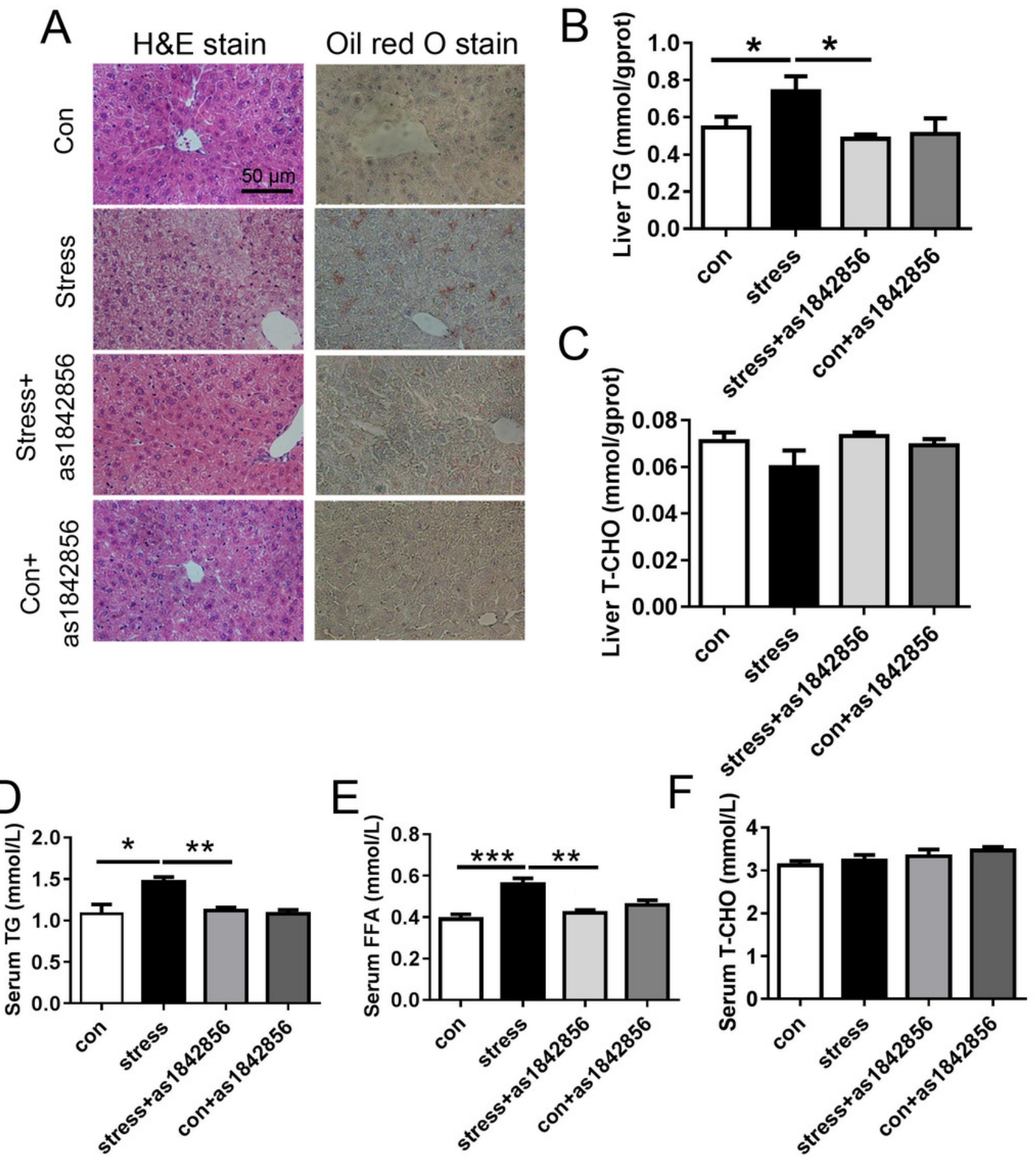


Figure 4

Effects of stress and as1842856 on liver lipid metabolism genes in mice after 6 weeks.

(A-C) Relative mRNA levels of genes involved in hepatic TG synthesis. (D-F) Relative mRNA levels of genes involved in fatty acid transport. (G-N) Relative mRNA levels of genes involved in fatty acid oxidation. ${ }^{*} p<0.05,{ }^{* *} p<0.01$. Date presented as mean $\pm S E M, n=6$. 


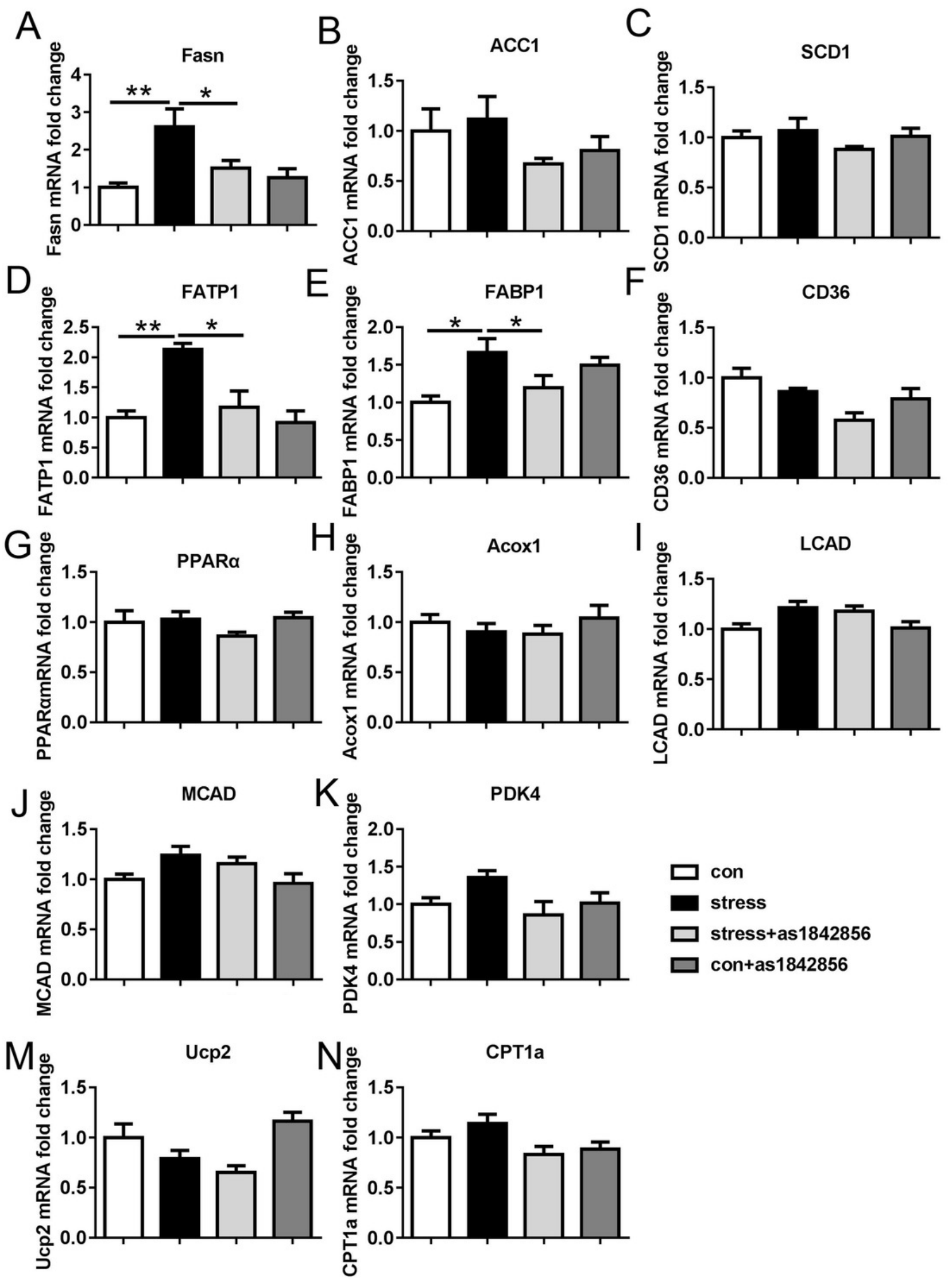


Figure 5

Effects of stress and as1842856 on cholesterol metabolism-related genes in mice after 6 weeks.

Liver was harvested and cholesterol metabolism-related genes were determined by realtimePCR. ${ }^{*} p<0.05, * * p<0.01$. Date presented as mean \pm SEM, $\mathrm{n}=6$. 


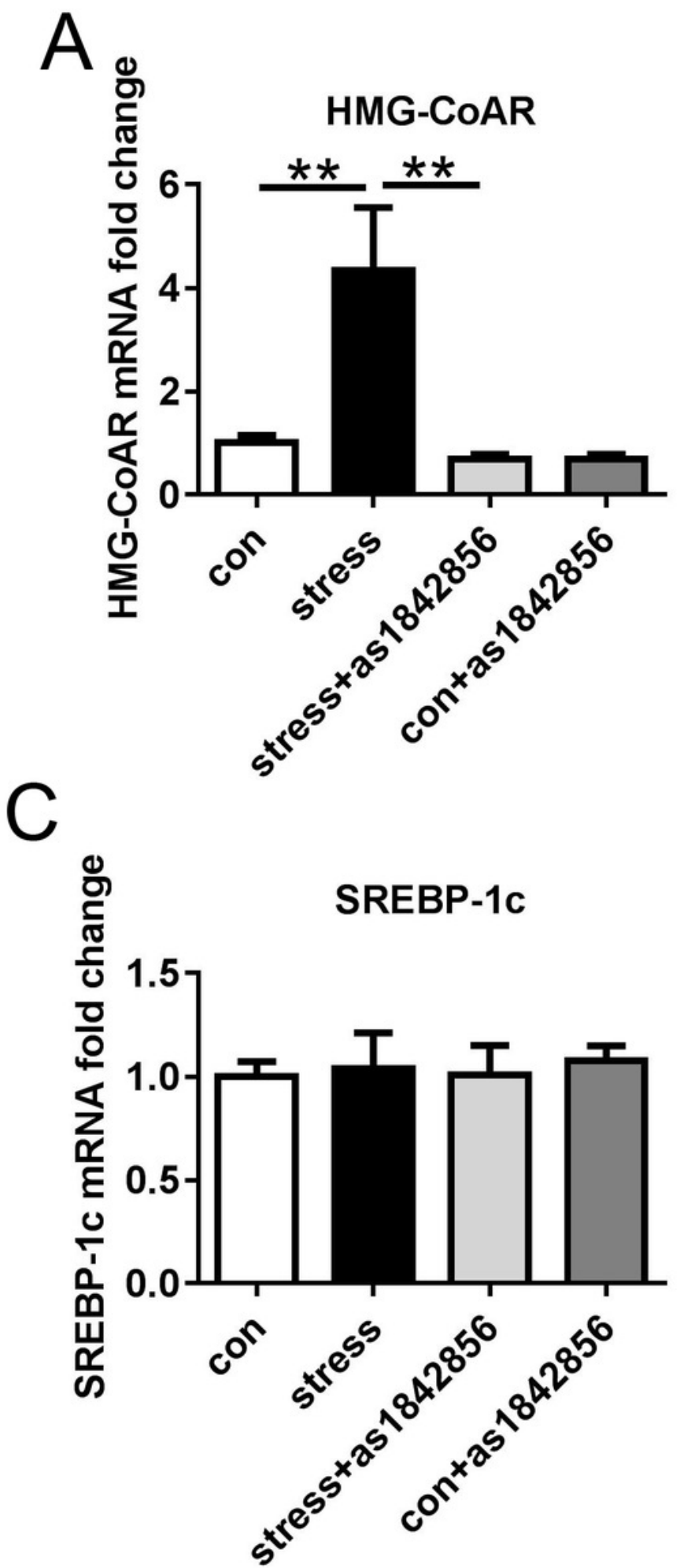

B

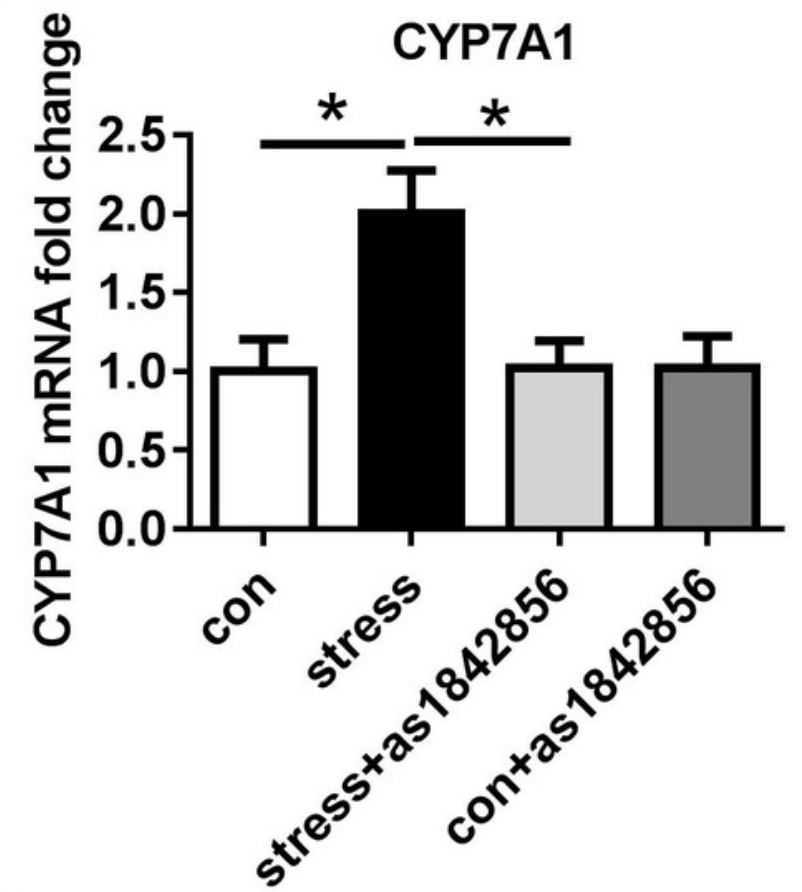

D

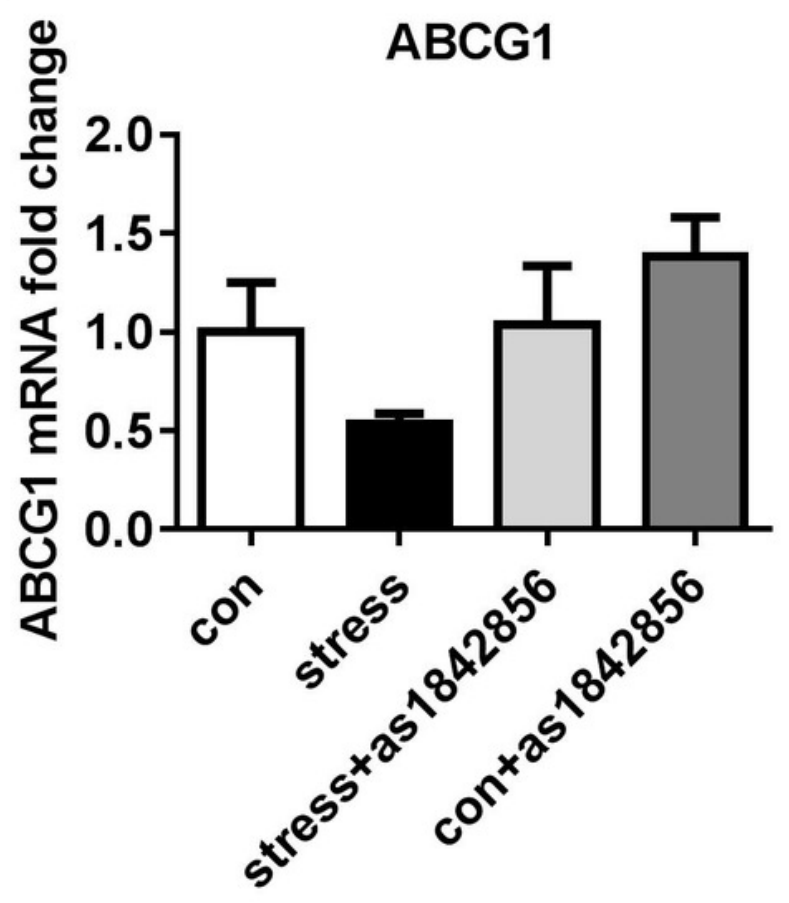




\section{Figure 6}

As1842856 protect Hepa1-6 cells against corticosterone-induced liver lipid deposition.

Effects of corticosterone and as1842856 on FoxO1 in Hepa1-6 cells after 48h. Corticosterone $(1 \mu \mathrm{M})$ increased the protein ( $\mathrm{A}$ and $\mathrm{B})$ and mRNA lever $(\mathrm{E})$ of FoxO1 expression and its downstream gene, PEPCK (F), AND decreased the lever of $p$-FoxO1 protein (C) and $p$ FoxO1/FoxO1 (D), while as1842856 (1 $\mu \mathrm{M})$ could reverse this effect except the protein and mRNA lever of Fox01 expression. ${ }^{*} p<0.05 \square * * p<0.01 \square^{* * *} p<0.0001$. Date presented as mean $\pm S E M, n=3$. 


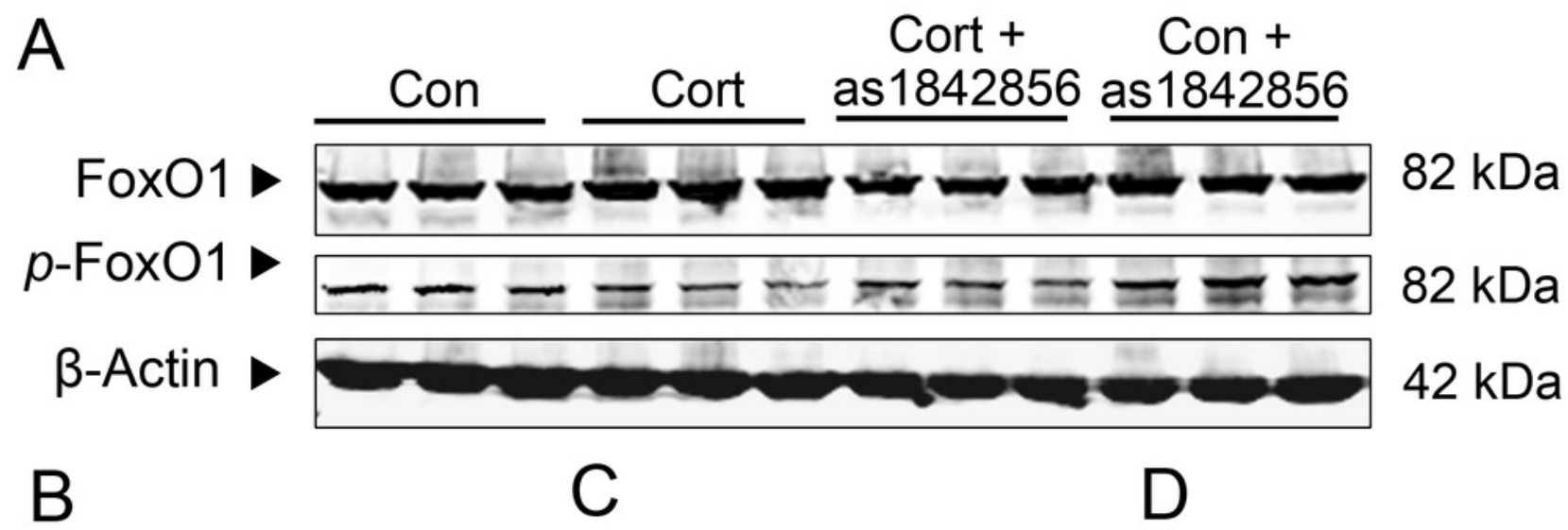

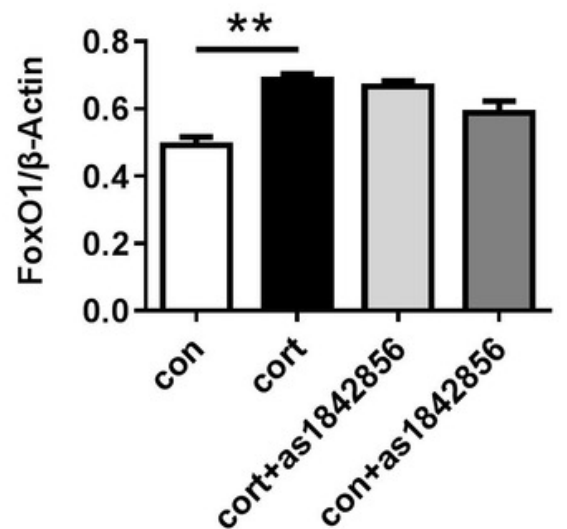

E
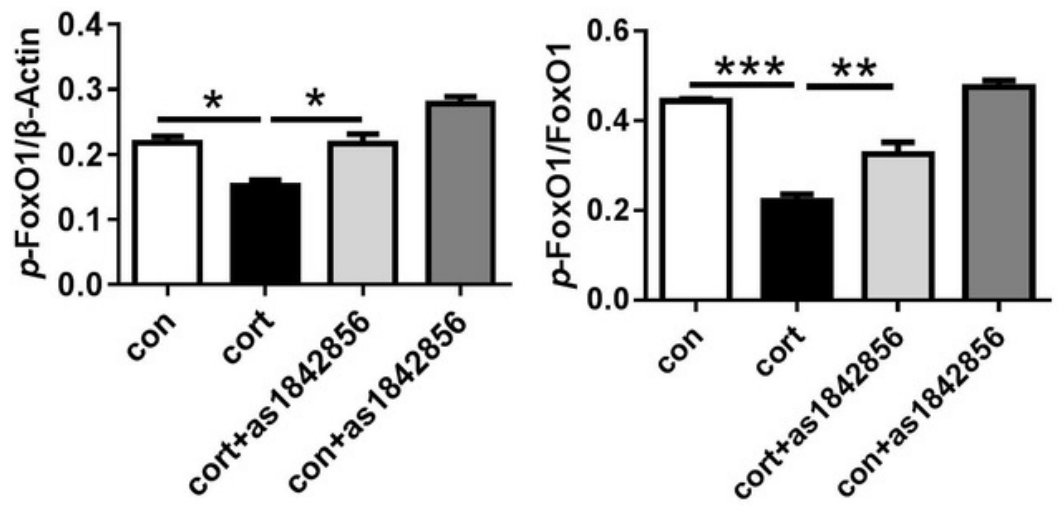

F
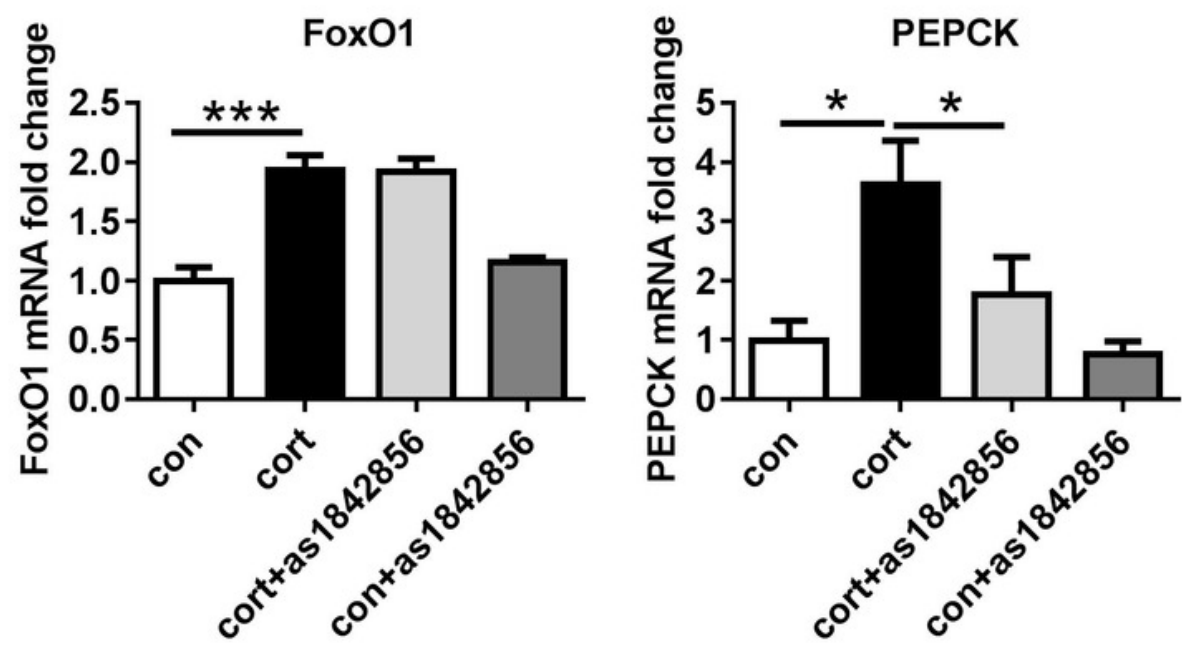
Figure 7

Effects of corticosterone and as1842856 on lipid deposition and TG synthesis genes in Hepa 1-6 cells after $48 \mathrm{~h}$.

(A) Representative images showed above from four groups. After treatment with $1 \mu \mathrm{m}$

Corticosterone or/and $1 \mu \mathrm{m}$ as 1842856 for $48 \mathrm{~h}$, the cells were stained with Oil red O. (B)

Corticosterone increased the genes' expression of Fasn, while as 1842856 could reverse this effect. (C and D) There was no significant difference among the four groups in the genes' expression of $\mathrm{ACC} 1$ and $\mathrm{SCD} 1 .{ }^{* * *} p<0.001$. Date presented as mean $\pm \mathrm{SEM}, \mathrm{n}=3$.

A

Oil red O stain
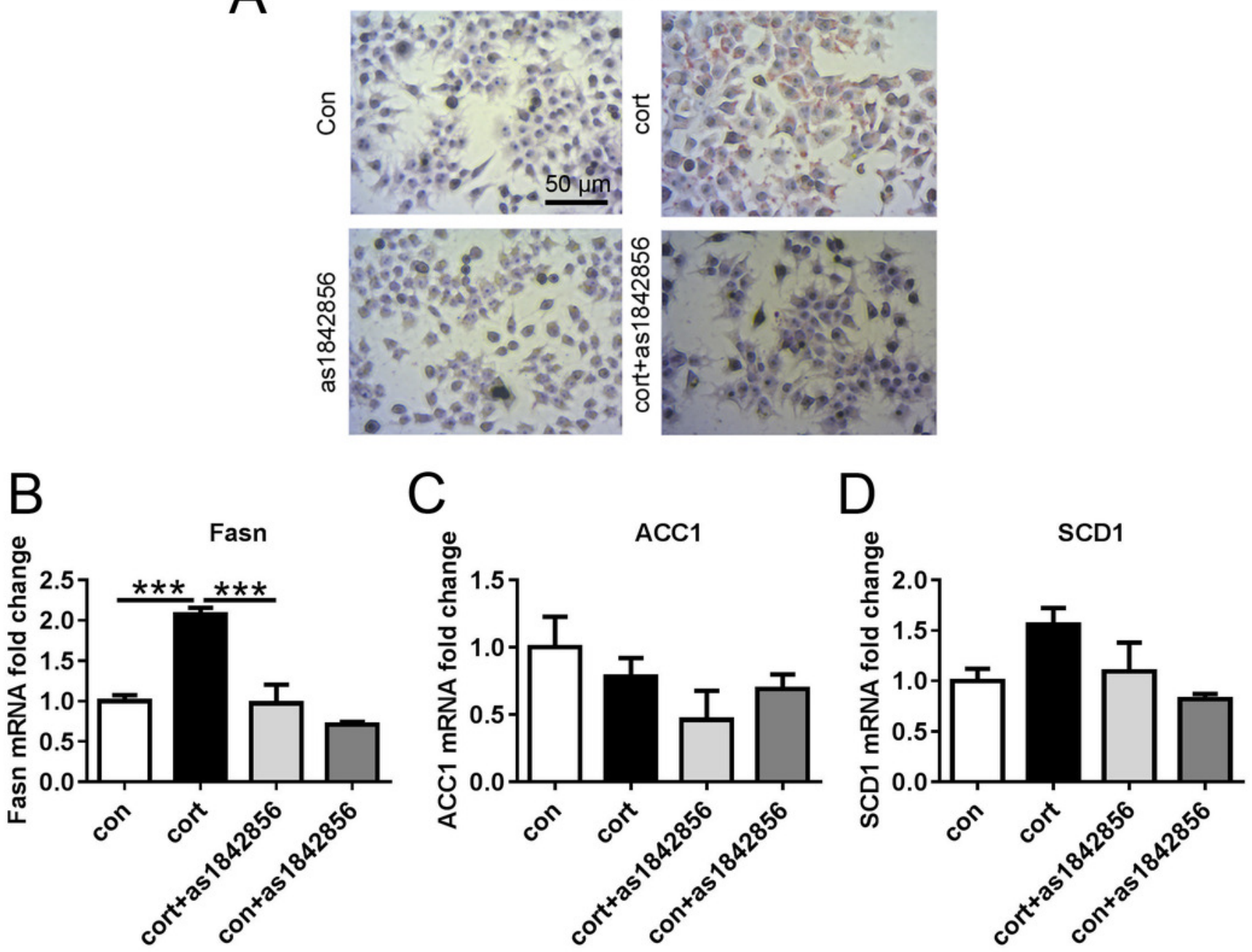